\title{
CENTROS DE VISITAÇÃO E EDUCAÇÃO AMBIENTAL EM ESCOLAS DE CAMPO GRANDE (MS)
}

Ana Caroline Queiroz Brites ${ }^{1}$

Ester Tartarotti ${ }^{2}$

Resumo: Estudamos as visitações de escolas da educação básica da cidade de Campo Grande a espaços educativos não formais institucionalizados; destacando o tema Educação Ambiental (EA). Verificamos que os professores de escolas públicas interessados pela utilização desses ambientes nos processos de ensino e aprendizagem preferem espaços institucionalizados. Os dados foram coletados por meio de instrumentos de pesquisa e coleta de dados aplicados nos próprios centros de visitação e aos professores da rede pública. Observamos indícios de superficialidade nos conteúdos de EA abordados nas escolas. Identificamos os fatores falta de tempo suficiente proporcionado pela grade curricular e transporte como principais entraves às visitações de alunos.

Palavras-chave: Educação Ambiental; Educação Não Formal; Escola; Centros de Visitação. 


\section{Introdução}

Entende-se como Educação Ambiental (EA) um conjunto de ensinamentos teóricos e práticos com o objetivo de levar á compreensão e de despertar a percepção do indivíduo sobre a importância de ações e atitudes para a conservação e a preservação do meio ambiente, em benefício da saúde e do bem-estar de todos (TEIXEIRA, 2007).

A EA esta incluída nas aulas teóricas e práticas do ensino formal, e este se baseia na maior parte das vezes, nos conteúdos curriculares propostos em livros didáticos. Segundo os Parâmetros Curriculares Nacionais (PCN) (BRASIL, 1998), a Educação Ambiental é classificada como um tema transversal focado na educação para a cidadania e requer que as questões sociais sejam apresentadas para a aprendizagem e a reflexão dos alunos, dando-lhe a mesma importância das áreas convencionais. Com isso o currículo ganha em flexibilidade e abertura, uma vez que os temas podem ser contextualizados de acordo com as diferentes realidades regionais.

Conforme a Lei 9.795/99, que estabelece as diretrizes e bases da educação nacional, em seu artigo $13^{\circ}$, conceitua-se as ações e práticas educativas voltadas para a sensibilização da coletividade sobre as questões ambientais e a sua organização e participação na defesa da qualidade do meio ambiente. A educação é definida a partir da conceituação dos espaços educativos nos quais o processo de ensino e aprendizagem é realizado. Partindo-se deste entendimento podemos compreender a educação formal como uma atividade realizada no espaço escolar, que está vinculado às Instituições Escolares da Educação Básica e do Ensino Superior, isto é, a escola com todas as suas dependências (JACOBUCCI, 2008).

Contrapondo-se a educação formal está a educação não formal, que é definida como qualquer atividade educacional organizada que, normalmente, se realiza fora dos enquadramentos do sistema formal de ensino (BIANCONI, 2005). Ainda devemos considerar os espaços não-formais de Educação denominados Instituições que são espaços regulamentados e que possuem equipe técnica responsável pelas atividades executadas, sendo o caso dos Museus, Centros de Ciências, Parques Ecológicos, Parques Zoobotânicos, Jardins Botânicos, Planetários, Institutos de Pesquisa (JACOBUCCI, 2008). Segundo DIAS (2003) a Educação Ambiental em centros de visitações pode ser definida como a que proporciona aprendizagem de conteúdos da escolarização em espaços como museus, 'centros de ciências, ou qualquer outro em que as atividades sejam desenvolvidas de forma bem direcionada.

A mudança trazida pela EA assume papel marcante na atualidade e consiste na aprendizagem ecológica para sustentabilidade, na qual o aluno se torna um agente articulador da promoção da qualidade de vida e do desenvolvimento de suas capacidades. A aprendizagem com escopo ecológico ensina o ser humano a viver em um mundo de respeito aos recursos naturais. O papel da educação, somente é ambiental, se pensarmos o ser humano como espécie que quer continuar habitando o planeta Terra.

Revbea, São Paulo, V. 11, № 1: 215-233, 2016. 
A educação deve orientar o uso sustentável do nosso planeta, incorporando uma análise da realidade socioambiental. Para essa aprendizagem, a educação não formal contribui para que os educandos possam conhecer locais em que a preservação da fauna e flora os ensine a necessidade de promover uma EA efetiva. O enfoque da temática ambiental por meio de visitas a espaços preservados, parques e museu são alternativas para aplicabilidade da EA na relação do homem com a natureza.

Para o desenvolvimento da proposta do Meio Ambiente como tema transversal, os PCNs alegam ser necessária uma política educacional de formação inicial e continuada dos professores, melhores condições salariais para os profissionais da área e estruturas de apoio, como acervo bibliográfico, recursos didáticos, instalações físicas adequadas para o desenvolvimento dos trabalhos. Sugerem que os professores estejam sempre se atualizando, trocando ideias, realizando parcerias com a comunidade escolar. Apontam o projeto político-pedagógico como o melhor caminho para que o Meio Ambiente seja pensado, discutido e proposto na escola. Indicam que para o bom desenvolvimento desta proposta, todos os professores, de forma interdisciplinar e transversal, possam estar envolvidos com este trabalho (ROSA, 2003).

A justificativa desta pesquisa está fundamentada no conhecimento a respeito da participação efetiva de escolas públicas de educação básica em espaços educativos não formais institucionalizados; tendo como referência a Educação Ambiental no âmbito dos temas transversais. Este estudo tem sua relevância ao diagnosticar a frequência de visitas das escolas aos espaços educativos não formais e principalmente buscar nos próprios professores da rede pública o interesse e o conhecimento sobre a importância e existência de centros de visitação na cidade de Campo Grande/MS. Compreender o entendimento do professor a respeito das oportunidades que os centros de visitação proporcionam aos processos de ensino e aprendizagem. A presente pesquisa visa também analisar a utilização dos espaços educativos; verificar o tema transversal Educação Ambiental ocorrido mediante as visitações de espaços não formais institucionalizados por Escolas públicas de Campo Grande (MS).

\section{Metodologia}

Neste trabalho de pesquisa realizamos um levantamento documental quanto a frequência de visitação de escolas públicas e privadas a três centros de visitação analisados, a saber: Centro de Educação Ambiental Leonor Reginato Santini, Centro de Reabilitação de Animais Silvestres e o Museu das Culturas Dom Bosco. As informações foram levantadas por meio de coleta de dados por meio de instrumento de pesquisa que versava sobre o nome da escola visitante e a data da visita. O período considerado na análise documental foi início de 2011 a setembro de 2013. O quantitativo de escolas do município foi coletado por meio de sites oficiais para Escolas Estaduais; Escolas Municipais (http://www.capital.ms.gov.br/semed/escolasMunicipais,

revista brasileira educação ambiental 
2013) e Escolas Particulares (http://www.sed.ms.gov.br/index.,2013). Nossa pesquisa também realizou um estudo sobre o entendimento do professor referente a Educação Ambiental na escola e a importância da utilização de instituições não formais de ensino na educação. O levantamento foi realizado em cinco escolas públicas de Campo Grande/MS na região do Anhanduí. As escolas inclusas na pesquisa foram: Escola Estadual Padre Mario Blandino, Escola Estadual Neyder Sueli, Escola Municipal Rafaela Abrão, Escola Municipal Wilson Taveira Rosalina e Escola Municipal Irene Szukala. Os dados foram coletados por meio de instrumentos de pesquisa e coleta de dados na forma de entrevista semi-estruturada aplicada aos professores de diferentes aréas da educação da rede pública de ensino, a citar pedagogia; 6 professores de biologia; 4 professores de português; 3 professores de educação física; 3 professores de artes; 2 professores de geografia; 1 professor de filosofia e teologia; 1 professor de química; 1 professor de física;1 professor de história. Os professores envolvidos tiveram participação voluntária no trabalho. A análise dos dados foi realizada de forma quantitativa e qualitativa incluindo observações dos discursos.

\section{Resultados}

Neste trabalho de pesquisa realizamos um levantamento documental quanto a frequência de visitação de escolas públicas e privadas a três centros de visitação analisados, a saber: Centro de Educação Ambiental Leonor Reginato Santini, Centro de Reabilitação de Animais Silvestres e o Museu das Culturas Dom Bosco. As informações foram levantadas por meio de coleta de dados baseada em instrumento de pesquisa que versava sobre o nome da escola visitante e a data da visita. O período considerado na análise documental foi de início de 2011 a setembro de 2013. Diversas visitas foram realizadas a cada centro para obtenção dos dados, estes foram plotados em gráficos convencionais para análise dos resultados da pesquisa (Figuras 1, 2, 3 ). As frequências de visitações de cada tipo de escola foram organizadas em Tabelas para melhor interpretação (Tabelas 1 e 2).

Tabela 1: Frequência de Visitações nos Centros de Visitações no Período de 2011 a setembro de 2013. Centro de Educação Ambiental Leonor Reginato Santini (CEA); Centro de Reabilitação

\begin{tabular}{|c|c|c|c|c|c|c|c|c|c|}
\hline Escolas & \multicolumn{3}{|c|}{ CEA } & \multicolumn{3}{|c|}{ CRAS } & \multicolumn{3}{|c|}{$\begin{array}{c}\text { Museu das Culturas Dom } \\
\text { Bosco }\end{array}$} \\
\hline Ano & 2011 & 2012 & 2013 & 2011 & 2012 & 2013 & 2011 & 2012 & 2013 \\
\hline E.E & $21,25 \%$ & $25 \%$ & $2,5 \%$ & $5 \%$ & $25 \%$ & $23,75 \%$ & $30 \%$ & $25 \%$ & $15 \%$ \\
\hline E.M & $12,62 \%$ & $54,36 \%$ & $2,91 \%$ & $6,79 \%$ & $26,21 \%$ & $10,67 \%$ & $31,06 \%$ & $66,01 \%$ & $4,85 \%$ \\
\hline E.P & $4,16 \%$ & $17,26 \%$ & $3,57 \%$ & $0,59 \%$ & $23,21 \%$ & $19,04 \%$ & $18,45 \%$ & $21,42 \%$ & $26,21 \%$ \\
\hline
\end{tabular}


Tabela 2: Porcentagem da frequência de visitações de escolas em relação ao total de escolas de Campo Grande-MS. Escolas Estaduais (E.E); Escolas Municipais (E. M.) e Escolas Particulares (E.P.). Centro de Educação Ambiental Leonor Reginato Santini (CEA); Centro de Reabilitação de Animais Silvestres (CRAS).

\begin{tabular}{|c|c|c|c|c|c|c|c|c|c|}
\hline Escolas & \multicolumn{3}{|c|}{ CEA } & \multicolumn{3}{c|}{ CRAS } & \multicolumn{3}{c|}{ Museu das Culturas Dom } \\
& $\mathbf{2 0 1 1}$ & $\mathbf{2 0 1 2}$ & $\mathbf{2 0 1 3}$ & $\mathbf{2 0 1 1}$ & $\mathbf{2 0 1 2}$ & $\mathbf{2 0 1 3}$ & $\mathbf{2 0 1 1}$ & $\mathbf{2 0 1 2}$ & $\mathbf{2 0 1 3}$ \\
\hline Estaduais & 17 & 20 & 2 & 4 & 20 & 19 & 24 & 20 & 12 \\
\hline Municipais & 13 & 56 & 3 & 7 & 27 & 11 & 32 & 68 & 5 \\
\hline Particulares & 7 & 29 & 6 & 1 & 39 & 32 & 31 & 36 & 27 \\
\hline Total & 37 & 105 & 11 & 12 & 86 & 62 & 87 & 124 & 44 \\
\hline
\end{tabular}

Dados coletados das redes de ensino público por meio de visitas a sites oficiais mostraram que quanto ao total de escolas existentes em Campo Grande-MS temos: 80 Escolas Estaduais; 103 Escolas Municipais e 168 Escolas Particulares.

No Centro de Educação Ambiental Leonor Reginato Santini no ano de 2011, 37 escolas realizaram visitas (Figura 1 e Tabela 1) e observou-se que a maior parte das visitas foram realizadas por escolas estaduais (Tabela 1), isto é, 17 escolas. Em segundo lugar estavam as escolas municipais com 13 visitações e o menor índice de visitações ocorreu em escolas particulares com 7 ocorrências (Figura 1 e Tabela 1). Confrontando estes dados com o número total de escolas públicas e privadas no município observamos que $21,25 \%$ das escolas estaduais, $12,62 \%$ das escolas municipais e $4,16 \%$ das escolas privadas realizaram visitações (Tabela 2). No ano de 2012, foi o ano em que o índice de visitação apresentou seu máximo, 105 escolas realizaram visitações ( Tabela 1); observa-se que a maior partes das visitas foram por escolas municipais (Figura 1), com 56 escolas. Em seguida estavam as escolas particulares (Figura 1 e Tabela 1) com 29 visitações e com um baixo índice as escolas estaduais com 20 visitações (Figura 1 e Tabela 1). Análisando estes dados em relação ao número total de escola públicas e privadas no município, podemos notar que $54,36 \%$ das escolas municipais, $25 \%$ das escolas estaduais e $17,26 \%$ das escolas particulares (Tabela 2) visitaram o centro. No ano de 2013 houve uma drástica redução nas visitações, segundo relatos de próprios funcionários, isso ocorreu devido a mudança de gestão da prefeitura, pois não houveram novos contratos, apenas 11 escolas fizeram visitações neste ano e a maioria foram escolas particulares, 6 visitações. Em segundo lugar, as escolas municipais com 3 escolas e por último as escolas estaduais com 2 ocorrência. (Figura 1 e Tabela 1). Confrontando os dados com o total de escolas do município, observamos visitações de $3,57 \%$ de escolas particulares, $2,91 \%$ de escolas municipais e $2,5 \%$ de escolas estaduais (Tabela 2). 


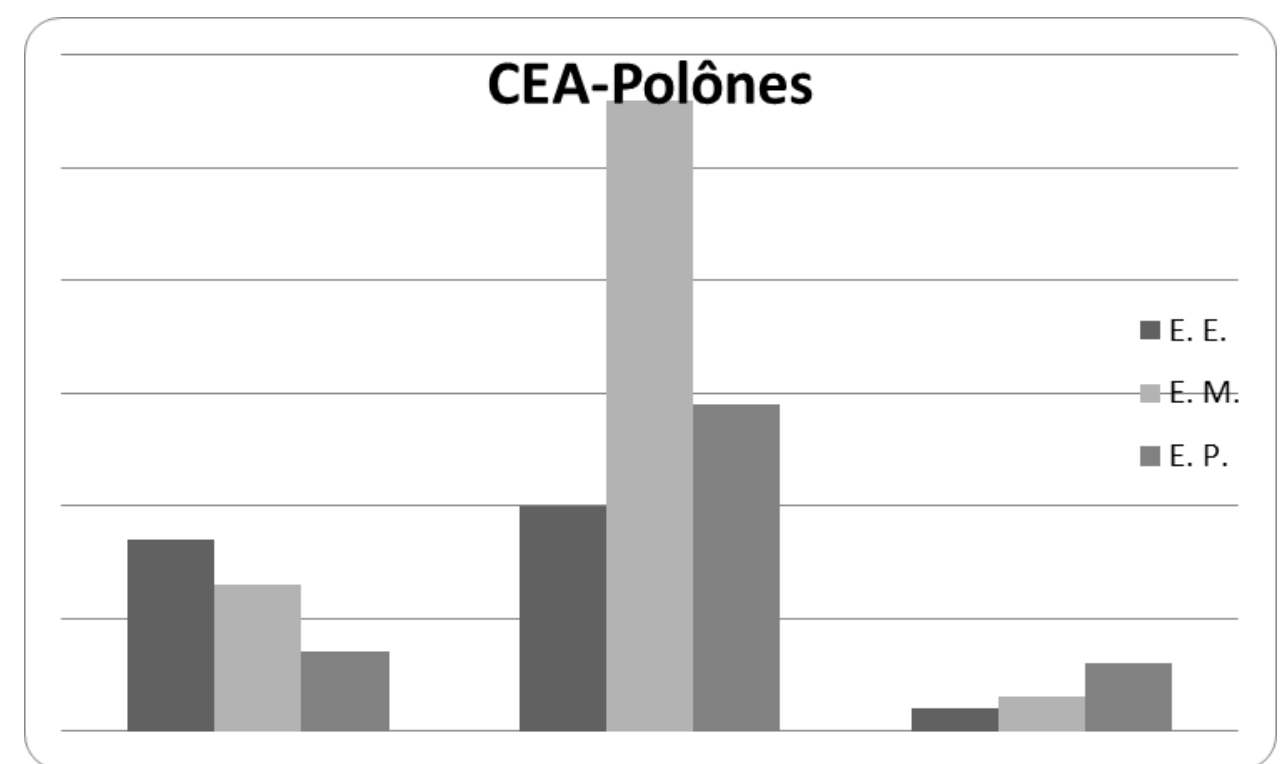

Figura 1: Frequência de visitação de Escolas Públicas e Privadas de Campo Grande-MS ao Centro de Educação Ambiental Leonor Reginato Santini (CEA) no período de 2011 a setembro 2013. Escolas Estaduais (E.E); Escolas Municipais (E. M.) e Escolas Particulares (E.P.). O eixo da ordenada refere-se ao número de escolas envolvidas em visitações. O eixo da abcissa refere-se ao período analisado.

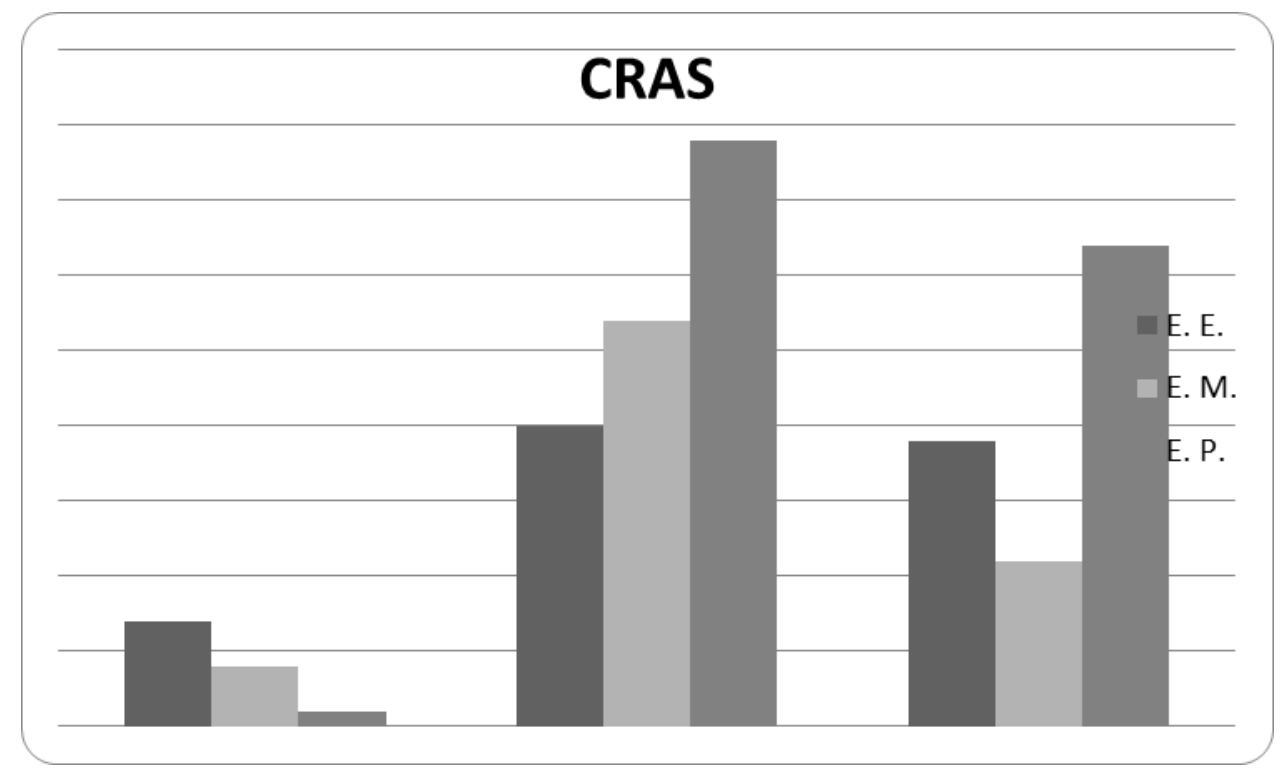

Figura 2. Frequência de visitação de Escolas Públicas e Privadas de Campo Grande-MS ao Centro de Reabilitação de Animais Silvestres (CRAS) no período novembro 2011 a setembro 2013. Escolas Estaduais (E.E); Escolas Municipais (E. M.) e Escolas Particulares (E.P.). O eixo da ordenada refere-se ao número de escolas envolvidas em visitações. O eixo da abcissa refere-se ao período analisado. 


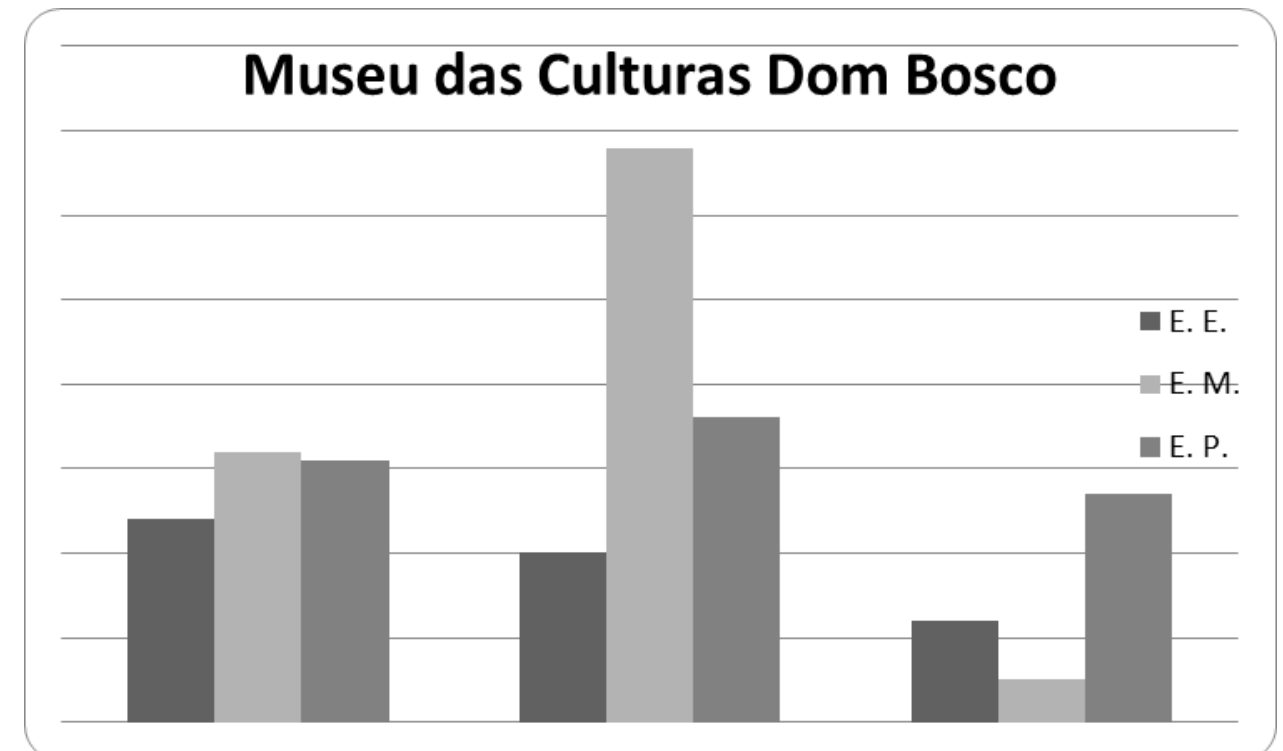

Figura 3. Frequência de visitação de Escolas Públicas e Privadas de Campo Grande-MS ao Museu das Culturas Dom Bosco no período de 2011 a setembro de 2013. Escolas Estaduais (E.E); Escolas Municipais (E. M.) e Escolas Particulares (E.P.). O eixo da ordenada refere-se ao número de escolas envolvidas em visitações. O eixo da abcissa refere-se ao período analisado.

No Centro de Reabilitação de Animais Silvestres no ano de 2011, não obtivemos dados do começo do ano, pois segundo relatos não foram encontrados, fizemos a coleta de dados apenas do final do ano de 2011, 12 escolas realizaram visitas (Figura 2 e Tabela 1). Observamos que a maior parte das visitas foram realizadas por escolas municipais (Tabela 1), 7 ocorrências; em seguida as escolas estaduais com 4 visitações (Figura 2 e Tabela 1) e o menor índice de visitações foi das escolas particulares com apenas 1 escola (Figura 2 e Tabela 1). Confrontando estes dados com o número total de escolas públicas e privadas do município, obtivemos $6,79 \%$ de escolas municipais, $5 \%$ das escolas estaduais e $0,59 \%$ das escolas particulares. No ano seguinte, o centro recebeu um total de 86 visitações de escolas (Tabela 1), 39 visitações por meio das escolas particulares (Figura 2 e Tabela 1), em segundo lugar com 27 ocorrências as escolas municipais (Figura 2 e Tabela 1) e por último as escolas estaduais, com 20 visitações (Figura 2 e Tabela 1). Analisando estes dados com o número total de escolas do município, obtivemos $26,21 \%$ das escolas municipais, $25 \%$ das escolas estaduais e $23,21 \%$ das escolas particulares (Tabela 2). No ano de 2013 computamos um total de 62 visitações de escolas, 32 dessas visitações foram das escolas particulares (Figura 2 e Tabela 1). Em segundo lugar as escolas estaduais, 19 ocorrências (Figura 2 e Tabela 1) e com baixo índice as escolas municipais com 11 visitações (Figura 2 e Tabela 1). Confrontando esses dados com o total de escolas públicas e privadas do município, obtivemos visitações em $23,75 \%$ das escolas estaduais, $19,04 \%$ das escolas particulares e $10,67 \%$ das escolas municipais (Tabela 2). 
No Museu das Culturas Dom Bosco no ano de 2011, 87 escolas realizaram visitações (Tabela 1); observa-se que a maior parte das visitas foram realizadas por escolas municipais (Figura 3 e Tabela 1), isto é, 32 escolas. Em segundo lugar estavam as escolas particulares (Figura 3 e Tabela 1) com 31 visitações e o menor índice ficou com as escolas estaduais com 24 ocorrências (Figura 3 e Tabela 1). Confrontando estes dados com o número total de escola públicas e privadas do município, obtivemos que $31,06 \%$ das escolas municipais, $30 \%$ das escolas estaduais e $18,45 \%$ das escolas particulares (Tabela 2). No ano de 2012, observamos um total de 124 visitações de escolas ao centro (Tabela 1). A maioria das visitas po escolas municipais (Figura 3 e Tabela 1) 68 visitações, em seguida com 36 visitações das escolas particulares (Figura 3 e Tabela 1) e por último as escolas estaduais, com 20 ocorrências (Figura 3 e Tabela 1). Analisando estes dados em relação ao número total de escolas do município, obtivemos $66,01 \%$ das escolas municipais, $25 \%$ das escolas estaduais e $21,42 \%$ das escolas particulares (Tabela 2). No ano de 2013, 44 escolas realizaram visitações (Tabela 1) observa-se que a maior parte foram realizadas por escolas particulares (Figura 3 e Tabela 1), com 27 ocorrências. Em segundo lugar estavam as escolas estaduais (Figura 3 e Tabela 1), com 12 visitações e por último as escolas municipais (Figura 3 e Tabela 1), isto é, 5 visitações. Confrontando estes dados com o número total de escolas privadas e públicas do município, obtivemos, $26,21 \%$ das escolas particulares, $15 \%$ das escolas estaduais e $4,85 \%$ das escolas municipais (Tabela 2 ).

O Instrumento de pesquisa e coleta de dados em forma de entrevista estruturada foi aplicado a 29 docentes de diferentes áreas do conhecimento que se disponibilizaram a participar da pesquisa. Nesta pesquisa os professores foram categorizados como P1- Professor 1 até P 29 - Professor 29. O convite a participação foi realizado em cinco escolas públicas de Campo Grande, somente os professores voluntários da pesquisa foram considerados neste estudo. Com relação a diversidade de áreas tivemos as seguintes colaborações: 7 professores de pedagogia; 6 professores de biologia; 4 professores de português; 3 professores de educação física; 3 professores de artes; 2 professores de geografia; 1 professor de filosofia e teologia; 1 professor de química; 1 professor de física;1 professor de história.

Quanto a experiência docente em sala de aula nossos professores entrevistados tinham deste 1 ano de experiência até 30 anos, classificados da seguintes forma: até 3 anos 4 professores; entre 3 e 5 anos 3 professores; de 5 a 10 anos 5 professores; de 10 a 15 anos 7 professores, de 15 a 20 anos 4 professores e acima de 20 anos 6 professores. No que se refere a formação pós-graduada do total de entrevistados 5 possuíam mestrado, 13 pósgraduação Lato senso e 11 não possuíam este tipo de formação.

De uma maneira geral os professores entrevistados declararam trabalhar temas ambientais em suas disciplinas. As manifestações foram afirmativas quanto a este questionamento presente no instrumento de pesquisa e coleta de dados. A citar tivemos os seguintes relatos: professores da pedagogia (P1 a 
P7) - relataram trabalhar por meio de vídeos, textos embasados em Educação Ambiental, nas séries iniciais com desenhos sobre a natureza; professores de biologia (P8 a P13) - trabalharam os temas conforme a ementa que vem da SED, com debates e projetinhos; professores de português (P 14 a P17) desenvolveram o tema por meio de discussões sobre fatos polêmicos e textos sobre a EA; professores de educação física (P18 a P20) - trabalharam por meio de projetos e debates sobre o assunto; professores de artes (P21 a P23) trabalharam com desenhos, releitura de obras de artes; professores de geografia (P24 e P25) - trabalharam com textos e vídeos; professor de física (P26) - com a conscientização do sujeito; professor de química (P27) - com projetos e produção de material didático feito pelos próprios alunos; professor de teologia e filosofia (P28) - de forma transversal citada de forma genérica e o professor de história (P29) - trabalharam com investigações, aulas práticas e textos bases sobre 0 assunto.

Quando questionados a respeito de uma disciplina específica de Educação Ambiental no Ensino Básico os professores das diferentes áreas expressaram suas opiniões de diferentes formas. Dos professores de pedagogia ( $\mathrm{P} 1$ a $\mathrm{P} 7)$ três entrevistados foram contrários e alegaram justificativas, tais como, currículo sobrecarregado, delegar a função as ciências e o motivo da Educação Ambiental estar inserida em outras áreas. Quatro entrevistados foram favoráveis justificando que da forma atual o assunto é tratado de maneira superficial, ainda que, uma disciplina específica traria conhecimentos mais fundamentados sobre a natureza e de uma forma geral melhoria na conscientização referente ao meio ambiente. Dos professores de Biologia (P8 a P13) quatro foram contrários a uma nova disciplina e observaram que o tema é transversal, que deve ser tratado em conjunto com várias disciplinas, ainda comentaram que não há mais espaço no curriculum. Dois professores foram favoráveis afirmando melhor formação da criança em relação ao ambiente em que vive e ressaltando a importância da inclusão no curriculum normal. Dos professores de Letras (P14 a P17), Língua Portuguesa, um professor relatou que não é favorável e comentou que a biologia tem projetos junto com outras disciplinas. Três professores foram favoráveis e colocaram como justificativa que a Educação Ambiental é mais voltada para ciências e biologia, ainda, mencionaram que o tema é muito relevante e que as gerações futuras deveriam ter melhor conhecimento e finalmente comentaram que o tempo de aula é pequeno e a abordagem da Educação Ambiental fica prejudicada em detrimento do assunto foco da sua disciplina. Dos professores de Educação Física (P18 a P20) dois foram contrários comentando que o tema deve ser trabalhado nas outras disciplinas. Um professor foi favorável pois acredita que uma melhor conscientização seria gerada para as futuras gerações. Dos professores de artes (P21 a P23) dois foram contrários e comentaram que deve ser trabalhado por todas as disciplinas. Um professor foi favorável e indicou que ocorreria maior conscientização quanto ao assunto. Dos professores de Geografia (P24 e P25) os dois entrevistados foram contrários pois entendem $\mathrm{o}$ assunto importante para própria geografia e também colocaram que todos devem trabalhar. O professor de física (P26)

revista brasileira educação ambiental 
expressou opinião favorável a inserção da disciplina e entende que a formação seria melhor. O professor de química (P27) foi contrário e acredita que deve estar permeado em várias disciplinas. O professor de teologia e filosofia (P28) foi favorável a uma disciplina específica e alegou a abordagem superficial realizada hoje nas escolas. O professor de história (P29) também foi favorável e observou que a disciplina específica poderia ser mais organizada, ter lugar próprio e melhoraria a compreensão dos alunos sobre o tema. Em uma análise geral 15 professores foram contrários a introdução de uma disciplina específica e 14 foram favoráveis, conforme todos os relatos comentados anteriormente.

Dos professores entrevistados na pesquisa 48,2\%, ou seja, 14 professores já haviam visitado algum centro de visitação com turmas de alunos. Destes, 12 professores visitaram os centros de visitação estudados em nosso trabalho da seguinte forma: 11 citações de visitas ao Museu das Culturas Dom Bosco, 9 citações ao Centro de Reabilitação de Animais Silvestres e 5 citações ao Centro de Educação Ambiental Leonor Reginato Santini. Dois professores realizaram visitas a outros Centros, Museus ou Parques do município de Campo Grande. Os professores que realizaram visitas ministram aulas nas disciplinas de história, geografia, artes, educação física, português, biologia e pedagogia.

Do total de professores entrevistados 51,8\% relataram não terem levado turmas para visitações e ministravam as disciplinas de filosofia e teologia, física e química. Os motivos aparentes para os professores não realizarem este tipo de atividade podem ser elencados da seguinte maneira: pouco conhecimento sobre o tema, pois a maioria dos professores relataram que nunca ouviram falar dos centros; alguns comentaram que não tem relação com a disciplina ministrada por eles e finalmente que a grade curricular não disponibiliza tempo suficiente para o assunto ser tratado.

De uma maneira geral, em relação a opinião sobre os centros, os entrevistados relataram que não tiveram dificuldades para agendar as visitações, eram os próprios professores que agendavam ou a diretoria da escola que fazia os agendamentos. A maioria dos professores não desistiram de suas visitações, entretanto, alguns declinaram por problemas de transporte. Em relação ao transporte, dos 14 professores que levaram alunos, a metade (7), usaram o transporte o público e os outros sete o transporte privado. Todos os entrevistados que visitaram os centros, com alunos ou sozinhos, relataram que as instalações são adequadas a qualquer série, desde que haja um planejamento prévio. De forma sucinta, em relação ao contexto abordado nos centros, os professores relataram que podem ser aplicados em sala de aula, seja por meio de resumos, relatos, trabalhos escolares, desenhos, discussões e até mesmo com a amostras de fotografias feitas nessas visitas, com tudo isso, eles puderam concluir que aulas como essas são muito satisfatórias e proveitosas para a aprendizagem dos alunos. Todos os entrevistados que já visitaram alguns dos centros elegidos na pesquisa, comentaram que voltariam ao centro, pois entenderam como uma atividade importante para a aprendizagem e também é uma forma lúdica, pois, os alunos se divertem e 
aprendem ao mesmo tempo. Nos relatos dos professores os mesmos disseram que voltariam a realizar visitas, pois os alunos têm a oportunidade de conhecer estes espaços de aprendizagem e há muitas turmas que poderiam se beneficiar de visitações como estas. Tivemos sugestões para melhorias nas condições de visitações, todas direcionadas a um apoio mais efetivo do transporte público, pois é extremamente difícil consegui-ló e quando se consegue é somente para uma ou duas turmas. Outra sugestão seria o lanche pois algumas visitações duram uma manhã ou parte da tarde inteira.

\section{Discussão}

A educação é um processo dinâmico em permanente construção. Devese, portanto, propiciar a reflexão, o debate e a sua própria modificação. As pessoas de todas as partes do mundo, principalmente educadores comprometidos com a proteção do meio ambiente reconhecem o papel central da educação na formação de valores e na ação social (CHAGAS, 2009).

Considerando toda essa importância da temática ambiental e a visão integrada do mundo, no tempo e no espaço, sobressaem-se as escolas, como espaços privilegiados na implementação de atividades que propiciem essa reflexão, pois isso, necessita de atividades de sala de aula e atividades de campo, com ações orientadas em projetos e em processos de participação que levem à autoconfiança, a atitudes positivas e ao comprometimento pessoal com a proteção ambiental implementados de modo interdisciplinar (DIAS, 1992).

Todos os professores entrevistados, das diferentes áreas do conhecimento, de alguma forma trabalham o tema Educação Ambiental em sala de aula, cada um com a sua abordagem, de acordo com a realidade da sua escola. As abordagens ocorreram das mais diversas formas, vídeos, textos embasados em Educação Ambiental; maquetes, debates e projetinhos. Nas séries iniciais predominaram desenhos sobre a natureza; discussões sobre fatos polêmicos, desenhos, releitura de obras de artes. A partir das entrevistas percebemos que grande parte das respostas foram muito genéricas para, de fato, indicarem uma efetiva abordagem da Educação Ambiental em sala de aula.

Segundo, Reis Júnior (2003) os professores, por desconhecerem a matéria e não estarem preparados para aproveitar as situações cotidianas quanto à Educação Ambiental, ficam presos ao livro didático sem, muitas vezes, contextualizar à realidade. Conteúdos que, na prática, poderiam ser explorados na própria região, valorizando a cultura, a história e as degradações ambientais do município.

Quando questionados sobre a introdução de uma disciplina especifica para EA no ensino básico, aproximadamente metade dos entrevistados foram contra inserção. Segundo a Lei no 9.795 de abril de 1999 Art. 2.ํ A Educação Ambiental é um componente essencial e permanente da educação nacional, devendo estar presente, de forma articulada, em todos os níveis e modalidades

revista brasileira educação ambiental 
do processo educativo, em caráter formal e não formal. Em seu artigo a referida lei coloca "Art. 10. A Educação Ambiental será desenvolvida como uma prática educativa integrada, contínua e permanente em todos os níveis e modalidades do ensino formal. $\S 1 . \circ$ A Educação Ambiental não deve ser implantada como disciplina específica no currículo de ensino."

Entretanto, tem sido observado que a Educação Ambiental vem sendo desenvolvida apenas por algumas disciplinas, é uma educação conservacionista apenas, e a Semana do Meio Ambiente vem sendo o pretexto para que as escolas se lembrem do ato de educar para o meio ambiente. A forma holística pela qual deveria ser tratada a Educação Ambiental fica esquecida ou ainda não foi compreendida pela escola e pelos educadores (TRAVASSOS, 2001).

A EA está sendo trabalhada teoricamente de forma transversal, ou seja, ela permeia todas as disciplinas da grade curricular, todas estão ligadas umas às outras por meio de um único tema. Observamos na pesquisa que nossos entrevistados trabalham o tema EA de maneira superficial sem conexão com as outras disciplinas.

Quase metade dos professores entrevistados foram a favor da criação de uma disciplina especifica para a EA. Argumentando que seria uma forma melhor para a conscientização ambiental dos estudantes. Os relatos dos professores favoráveis a inserção da disciplina específica referente a Educação Ambiental versaram sobre diversos fatores importantes, tais como, a alegação de que o assunto é tratado de forma superficial e que uma disciplina específica traria conhecimentos mais fundamentados e de uma forma geral melhoraria a conscientização referente ao meio ambiente. Afirmaram a possibilidade de uma melhor formação da criança em relação ao ambiente em que vive e ressaltaram a importância da inclusão no curriculum normal. Outros relatos indicaram que o tema é muito relevante e que as gerações futuras deveriam ter melhor conhecimento e ressaltaram que o tempo de aula é pequeno e a abordagem da Educação Ambiental fica prejudicada em detrimento do assunto foco da sua disciplina, finalmente observaram que a disciplina específica poderia ser mais organizada.

No entanto, segundo Travassos (2001) criar a disciplina Educação Ambiental para fazer parte da grade curricular, como foi sugerido por alguns professores entrevistados para esta pesquisa, não é a solução para tornar a Educação Ambiental eficiente. Trata-se, primeiro, de uma conscientização. Apesar dos dispositivos legais existirem, as escolas públicas e particulares ainda não assimilaram ou não entenderam como devem implementar a Educação Ambiental em seus programas.

Introduzir a EA nas escolas tem se mostrado uma tarefa cansativa. Existem grandes dificuldades nas atividades de sensibilização e formação, na implantação de atividades e projetos e, principalmente, na manutenção e continuidade dos já existentes. Segundo Andrade (2000) fatores como o tamanho da escola, número de alunos e de professores, predisposição destes 
professores em passar por um processo de treinamento e vontade da diretoria de realmente implementar um projeto ambiental que irá alterar a rotina da escola podem servir como obstáculos à implementação da Educação Ambiental nas escolas.

Segundo Oliveira (2000) tem-se três dificuldades a serem vencidas no processo da efetiva implementação da Educação Ambiental no âmbito escolar: a busca de alternativas metodológicas; a barreira rígida da estrutura curricular em termos de grade horária, conteúdos mínimos e avaliação; a sensibilização do corpo docente frente às dificuldades de novos desafios e reformulações que exigem trabalho e criatividade.

Segundo Effting (2007) conteúdos ambientais permeando todas as disciplinas do currículo e contextualizados com a realidade da comunidade ajudará o aluno a perceber a correlação dos fatos e a ter uma visão integral do mundo em que vive. Para isso a Educação Ambiental deve ser abordada de forma sistemática e transversal, em todos os níveis de ensino, assegurando a presença da dimensão ambiental de forma interdisciplinar nos currículos das diversas disciplinas e das atividades escolares.

Aplicar a interdisciplinaridade ainda requer maior planejamento. O autor Oliveira (2000) sugere os seguintes passos para a busca de alternativas na escola com equipes de coordenação multidisciplinar: formulação de um projeto pedagógico que reflita o espaço sociopolítico- econômico- cultural da escola; levantamento de situações-problemas relevantes referente à realidade em que a escola está inserida; estruturação de uma matriz de conteúdos intercruzados versus situações problemas; realizações de seminários, encontros, debates entre professores para compatibilizar as abordagens dos conteúdos com as situações problema.

Ocorrendo todo um planejamento pode ser possível que a EA seja trabalhada de forma correta em todas as disciplinas da grade curricular de ensino.

Segundo Japiassu (1976, p.39),

Um objeto só pode exigir uma pesquisa interdisciplinar na medida em que seus participantes forem capazes de adotar certa linguagem comum (a primeira implica, pois, a segunda). Por sua vez, uma linguagem só se verificará como efetivamente comum, quando for capaz de medirse com um objeto também comum (a segunda implica a primeira).

Essa interdisciplinaridade depende de um treinamento e de capacitação para os professores. Trata- se de trabalhar com várias disciplinas ao mesmo tempo. Como afirma Japiassu (1976, p.39), 
O domínio do interdisciplinar é vasto e complexo. Devido, principalmente, à falta de troca de conhecimento entre os especialistas. Para superar este problema devem-se engajar cada vez mais na pesquisa de aproximações, de interações e dos métodos comuns às diversas especialidades.

Possivelmente quando houver treinamento adequado e as escolas e professores estiverem devidamente capacitados, a interdisciplinaridade seja trabalhada de forma correta e o conteúdo abordado de forma efetiva e não superficialmente como verificamos em vários relatos. Uma oportunidade para se trabalhar Educação Ambiental nas diferentes áreas do conhecimento é a visita a centros educativos não formais, tais como parques, museus, centros de Educação Ambiental. Uma boa opção para os professores do ensino básico é levar turmas para centros de visitação institucionalizados que contam com apoio de monitores, trilhas planejadas e ainda roteiros de observação de museus por exemplo.

Segundo Botelho e Morais (2004), os Museus/Centros de Ciência possuem uma função pedagógica, tal como acontece na escola, embora distinta. $\mathrm{O}$ contexto das suas atividades pode ser considerado, à semelhança do contexto de sala de aula, como uma prática pedagógica, determinando uma relação particular entre os sujeitos presentes nesse contexto.

Nesta pesquisa, como já comentamos, elegemos para estudo espaços de ensino não formal institucionalizados. A importância dos espaços de ensino não formais remete-se ao conceito de educar ao ar livre ou exploração da educação no meio ambiente, que é uma estratégia pedagógica onde se procura aprender por meio do contato com a natureza ou com o contexto biofísico e sociocultural do entorno da escola ou da comunidade. Estes espaços permitem a visitação dos alunos e mostram a importância de se preservar o meio ambiente, ainda estimulam ampla discussão dos aspectos biológicos, geográficos, históricos, políticos, econômico, social e cultural, visando a leitura da realidade.

O Centro de Educação Ambiental Leonor Reginato Santini - CEA Polonês - analisado em nosso estudo tem como objetivo contribuir para a promoção e apoio ao processo de Educação Ambiental em Campo Grande. Às margens do Córrego Sóter e com uma estrutura física dotada de auditório, espaço multiuso, casa sustentável, trilha ecológica, observatório e espaços de convivência, o local é um convite perfeito à reflexão e a vivência de práticas sustentáveis (http://ceapolones.blogspot.com.br).

O Centro de Reabilitação de Animais Silvestres (CRAS), localizado no Parque Estadual do Prosa, recebe animais silvestres apreendidos durante operações de fiscalização efetuadas pela Polícia Militar, IBAMA e Corpo de Bombeiros. Atualmente o centro é referência na preservação de espécies da fauna brasileira que se encontram sob risco de extinção. Desde sua criação em 1988 o centro já recebeu mais de 20 mil animais oriundos do tráfico, de Revbea, São Paulo, V. 11, № 1: 215-233, 2016. 
doações da população, de casos de atropelamentos e acidentes rodoviários (http://www.bonitoweb.com.br).

O Museu das Culturas Dom Bosco também analisado em nossa pesquisa trata da história natural e foi idealizado pela Inspetoria Salesiana de Mato Grosso localizado em Campo Grande (MS) no Parque das Nações Indígenas. Mais conhecido como museu do Índio, foi criado em 1950. O museu é conhecido mundialmente pelo rigor científico de seu considerável acervo. O museu abriga uma coleção com cerca de 40.000 peças divididas entre diferentes áreas como mineralogia, paleontologia, etnografia, arqueologia e zoologia e mais de 5.000 peças indígenas de várias culturas (http://www.mcdb.org.br).

De acordo com os professores entrevistados deste trabalho que já foram e levaram turmas em centros de visitações, isto é, $48,2 \%$ já haviam visitado algum centro de visitação com turmas de alunos. A maioria dos professores visitaram os centros de visitação estudados em nosso trabalho, ou seja, Museu das Culturas Dom Bosco, Centro de Reabilitação de Animais Silvestres e Centro de Educação Ambiental Leonor Reginato Santini. Tal observação indica que os centros institucionalizados são opções mais procuradas pelos professores, possivelmente em função da organização e atividades oferecidas por estes centros de visitação. Entre os professores de diferentes disciplinas entrevistados observamos que as áreas de história, geografia, artes, educação física, português, biologia e pedagogia realizaram visitas.

As disciplinas de filosofia e teologia, física e química não mostraram interesse nos centros de visitação. De uma forma geral, os professores que não entendem as atividades de visitação como importantes apresentaram como motivos aparentes os seguintes: pouco conhecimento sobre o tema, pois a maioria dos professores relataram que nunca ouviram falar dos centros; alguns comentaram que não tem relação com a disciplina ministrada por eles e finalmente que a grade curricular não disponibiliza tempo suficiente para o assunto ser tratado.

A questão ambiental ainda é muito teórica, parte dos professores ainda lutam para ficarem dentro de sala de aula e se remetem apenas aos livros didáticos. Podemos observar está conduta em alguns dos relatos abaixo:

Professor 1: " a grade curricular é muito extensa, e o tempo muito curto, não tenho tempo para aulas assim."

Professor 2: "a minha matéria não se encaixa em aulas como essas. "

Segundo Bertoletti (2003) os espaços não formais de ensino não devem ser vistos como concorrentes da escola, mas podem complementar a educação que aí se efetua. Constituem um espaço não formal, capaz de assumir algumas funções educativas que a escola tem tido dificuldade em concretizar. Para Vieira et al. (2005) esses espaços oferecem a oportunidade de suprir, pelo menos em parte, algumas das carências da escola como a falta de 
laboratórios, recursos audiovisuais, entre outros, conhecidos por estimular as aprendizagens.

Segundo FREITAS (1999), as escolas e os professores deveriam encarar os Museus/Centros de Ciência como importantes recursos educativos, incluindo-os explicitamente na planificação e implementação das suas atividades didáticas, tanto em relação com as temáticas curriculares disciplinares, como numa perspectiva de abordagem interdisciplinar. É essencial que a ida a estes locais não surja de episódios isolados das restantes atividades curriculares, mas seja cuidadosamente preparada por professores e alunos.

Enfim, os espaços não formais são recursos pedagógicos complementares ás carências da escola, que tendem a buscar diferentes formas de ensinar, tornando o ensino mais prazeroso e aumentando 0 interesse dos estudantes. A visitação a parques e museus transmite aos alunos uma visibilidade das questões ambientais. Além de difundir a ideia de que a EA não pode ser isolada, deve ser discutida associando as ações culturais, sociais e políticas.

Entre nossos professores entrevistados que conhecem e levaram turmas aos centros elegidos, vimos o interesse e empenho deles por esse tipo de aula.

Professor 3: " são mais proveitosas, por que tudo que se pega, se vê, se sente, define melhor o que está sentindo."

Em relação ao contexto abordado nos centros, os professores relataram de forma geral que podem ser aplicados em sala de aula, por meio de resumos, relatos, trabalhos escolares, desenhos, discussões e até mesmo com a amostras de fotografias feitas nessas visitas, com tudo isso, eles puderam concluir que aulas como essas são muito satisfatórias e proveitosas para a aprendizagem dos alunos.

Para Vieira et al. (2005) a visita a um espaço não formal desperta uma animação possível de ser aproveitada, dê preferência, anterior a visita. Em nosso estudo observamos também que as dificuldades são as principais barreiras para que as visitações ocorram, dentre elas, a que mais se destacou foi o Transporte. Em relação as dificuldades que os professores enfrentam em sair escola, Vieira et al. (2005) também apontaram o transporte e as despesas em geral, como grandes empecilhos para a realização desse tipo de aula.

Ao analisar a frequência de visitações de escolas aos centros estudados, vimos que há uma variação durante os anos de 2011 a 2013. Constatamos que o ano em que houve mais visitações foi o de 2012 nos três centros de visitação estudados. O ano de 2013 não foi muito proveitoso para os centros, um dos motivos para isso, foi a mudança de gestão da prefeitura de Campo GrandeMS pois muitos contratos não foram renovados. Apresentamos dois depoimentos que atestam a informação. Segundo relatos dos funcionários do CEA os contratos foram até dezembro de 2012 e o centro ficou sem jardineiro, 
sem merenda, sem ônibus para o transporte. No CRAS os relatos indicaram falta de funcionários para atender o público interessado. Adicionalmente, observamos que no ano de 2013 a frequência de visitação foi maior entre as escolas particulares para os três centros de visitação.

Relacionado as escolas públicas e privadas do município, não podemos comentar qual delas tem o maior interesse por visitação, mais vimos que as escolas particulares e as escolas municipais foram as que mais manifestaram interesse por estas atividades extra classe. A aula não formal desperta um maior interesse no aluno, proporcionando uma melhor assimilação dos conteúdos didáticos das aulas e a exploração das questões ambientais, sociais, culturais que perfazem o cotidiano escolar e familiar. Assim, a EA não formal é positiva para o processo de aprendizagem.

De uma maneira geral nosso trabalho mostrou que os professores abordam o tema Educação Ambiental em suas aulas cotidianas, entretanto, houveram indícios de superficialidade no tratamento do tema. Os professores manifestaram posições favoráveis e contrárias a inserção de uma disciplina específica de Educação Ambiental na escola, mas um fator relevante ficou claro, a forma aplicada hoje nas escolas precisa ser melhor planejada e pensada, pois a problemática exposta pelos professores mostrou em diversas análises que este tipo de educação ainda é tratada de forma incipiente nas instituições de ensino. O tema EA na escola é prejudicado em detrimento do assunto foco das disciplinas devido a grade curricular apertada. Nosso trabalho também indicou que os professores interessados em atividades em centros de visitação não formais procuram em sua maior parte os centros institucionalizados e trabalham os conteúdos em sala de aula. Observamos ainda que professores não interessados nas visitações têm poucas informações ou conhecimento referentes aos centros e forte influência da falta de tempo suficiente proporcionada pela grade curricular. De grande relevância foi identificação do fator transporte como principal entrave a ida das turmas de alunos a centros de visitação, o apoio do transporte público se mostrou precário e pouco disponível. No município de Campo Grande ainda cabe ressaltar que o índice de visitações por escolas a centros de visitação no ao de 2013 foi baixo por influência da mudança de gestão da prefeitura, pois muitos contratos não foram renovados.

\section{Referências}

BERTOLETTI, J. Museu de Ciências e Tecnologia da Pontificia Universidade Catolica do Rio Grande do Sul (MCT/PUCRS). Cultura Científica, 2003. Disponível em: (http://www.comciencia.br/reportagens/cultura/cultura16.shtml). Acessado em: 25/10/2013

BIANCONI, M.L.; CARUSO, Fr. Educação Não-Formal. Ciências e cultura. v.57. n.4 p. 20 out/dez. 2005. 
BOTELHO, A.; MORAIS, A.M. O que fazem os alunos num centro de ciênciauma análise das interaçcões com módulos científicos participativos. Revista Portuguesa de Educação, v.16, n.1, p. 157-192. 2003.

BRASIL. Lei no 9.795 - 27 Dez. 1999. Dispõe sobre a Educação Ambiental. Disponível em: <http://www.planalto.gov.br/ccivil 03/leis/19795.htm>. Acesso em: 25/11/2013

BRASIL. Ministério da Educação. Parâmetros Curriculares Nacionais. Meio ambiente e saúde. v. 9. Brasília: MEC, 1997.

CEA POLONÊS - Centro de Educação Ambiental Leonor Reginato Santini. Blogspot. Disponível em <http://ceapolones.blogspot.com.br/> Acessado em: 20/11/2013.

CHAGAS, I.D. A Educação Ambiental e a Inclusão Local. Monografia (Trabalho de Conclusão de Curso) - Instituto Federal de Educação Ciência e Tecnologia do Sul de Minas Gerais - Campus Muzambinho. 2009.

CRAS - Centro de Reabilitação de Animais Silvestres. Disponível em $<$ http://www.bonitoweb.com.br/>. Acessado em: 21/11/2013.

DIAS, G.F. Educação Ambiental: princípios e práticas. $8^{a}$ ed. São Paulo: Gaia, 2003.

EFFTING, T.R. Educação Ambiental nas Escolas Públicas: Realidade e Desafios. Marechal Cândido Rondon, 2007. Monografia (Pós Graduação em "Latu Sensu" Planejamento Para o Desenvolvimento Sustentável) - Centro de Ciências Agrárias, Universidade Estadual do Oeste do Paraná - Campus de Marechal Cândido Rondon, 2007.

FREITAS, M. Os Museus e o Ensino das Ciências. Comunicar Ciência. Ministério da Educação - Departamento de Ensino Secundário, v.1, n.3, p. 1-8, set/out, 1999.

JACOBUCCI, D.F.C. Contribuições dos Espaços Não formais de Educação para Formação de Cultura Científica. Em Extensão, v.7, p. 55-66, 2008.

JAPIASSU, Hilton. Interdisciplinaridade e Patologia do saber. Rio de Janeiro: Imago, 1976.

MUSEU das Culturas Dom Bosco. Disponível em <http://www.mcdb.org.br/> Acessado em: 21/11/2013.

OLIVEIRA, E.M. A Educação Ambiental uma Possível Abordagem. Brasília, IBAMA, 2000.

PRAXEDES, G.C. A Utilização de Espaços de Educação Não formal por Professores de Biologia de Natal- RN. 2009. 167 f. Dissertação (Mestrado) Universidade Federal do Rio Grande do Norte. Centro de Ciências Exatas e da Terra. Programa de pós Graduação em Ensino de Ciências Naturais e Matemática. 2009. 
REIS JÚNIOR, A.M. A formação do professor e a Educação Ambiental. 2003. 194 f. Dissertação (Mestrado em Educação) - Faculdade de Educação. Universidade Estadual de Campinas. 2003.

ROSA, I.M.C. O Meio Ambiente como Tema Transversal na Escola: Limites e Desafios. 2001. Dissertação (Mestrado) Universidade Católica de Goiás, Goiânia. 2001. (I EDIPE I Encontro Estadual de Didática e Prática de Ensino 30/11 a 02/12/2003 - Goiânia - GO )

SED - Secretária de Estado de Educação do Mato Grosso do Sul. Escolas estduais e particulares. Disponível em $<$ http://www.sed.ms.gov.br/index.,2013> Acessado em : 29/11/2013.

SEMED - Secretária Municipal de Educação. Escola Municipais. Disponível em $<$ <ww.capital.ms.gov.br/semed/escolasMunicipais>. Acessado em: 29/11/2013.

TEIXEIRA, A.C. Educação Ambiental: Caminho para a Sustentabilidade. Revista Brasileira de Educação Ambiental, v.2 p. 23-31,fev.2007.

TRAVASSOS, E.G. A Educação Ambiental nos Currículos: dificuldades e desafios. Revista de Biologia e Ciências da Terra. v.1. n.2. p. 0. 2001.

VIEIRA, V. et al. Espaços Não-formais de Ensino e o Currículo de Ciências. Ciência e Cultura. v.57 n.4. p.21-23. out/dez 2005. 